\section{Detection of Citrus Leaf and Seed Glycoproteins using Biotinylated Lectin Probes}

\author{
Randall P. Niedz ${ }^{1}$, Michael G. Bausher ${ }^{2}$, and C. Jack Hearn ${ }^{3}$ \\ Horticultural Research Laboratory, U.S. Department of Agriculture- \\ Agricultural Research Service, 2120 Camden Road, Orlando, FL 32803 \\ Additional index words. Concanavalin A, SDS-PAGE, electroblotting
}

\begin{abstract}
Citrus leaf and seed glycoproteins were detected after sodium dodecyl sulfate polyacrylamide gel electrophoresis (SDS-PAGE) and electroblotting onto polyvinylidene difluoride (PVDF) membrane when probed with biotinylated lectin at $1 \mu \mathrm{g} \cdot \mathrm{ml}^{-1}$. Four lectins representing three carbohydrate-binding groups were used as probes. A preformed avidin-biotin-complex (ABC) was used to detect the glycoprotein-bound lectins and resulted in dark bands and little background staining. Concanavalin $A$ (ConA) and wheat germ agglutinin (WGA) resulted in the darkest-staining bands. The four Citrus spp. and one related species studied had unique seed glycoprotein profiles when probed with ConA and WGA. This procedure might be useful in clarifying citrus taxonomy, providing genetic markers, and in physiological studies involving glycoproteins.
\end{abstract}

Citrus taxonomy is an unresolved, complex problem. For instance, the number of species reported to comprise the genus ranges from 162 (Tanaka, 1977) to three (Barrett

Received for publication 30 Apr. 1990. Mention of a trademark, warranty, proprietary product, or vendor does not constitute a guarantee by the U.S. Dept. of Agriculture and does not imply its approval to the exclusion of other products or vendors that may also be suitable. We thank Delores F. Jordan for her competent assistance and Randall C. Smith for preparing the figures. The cost of publishing this paper was defrayed in part by the payment of page charges. Under postal regulations, this paper therefore must be hereby marked advertisement solely to indicate this fact.

'Research Geneticist.

'Research Plant Physiologist.

${ }^{2}$ Research Geneticist. and Rhodes, 1976). Barrett believes the facultative apomictic reproductive system of Citrus is responsible for much of the confusion over what constitutes a true species. Citrus spp. relationships have been studied by numerical taxonomy (Barrett and Rhodes, 1976), isozyme profiles (Torres et al., 1978), chemical constituents (Rouseff et al., 1987), and Ouchterlony immunoprecipitation patterns (Morimoto, 1977).

This paper presents a sensitive procedure to detect specific glycoproteins based on the avidin-biotin-complex (ABC) method of Hsu et al. (1981) by probing electroblotted citrus leaf and seed proteins with biotinylated lectins. Lectins are carbohydrate-binding proteins, not immunologically derived and generally of plant origin. They have been used to isolate glycoproteins by affinity chromatography (Chicken and Sharom, 1983), to study carbohydrate structure (Chu et al., 1981) and, when conjugated to ferritin, fluorescein isothiocyanate, Horseradish peroxidase, or biotin derivatives, as histochemical and cytochemical probes (Pena et al., 1981). Each lectin's characteristic carbohydratebinding specificity can distinguish glycoproteins separated electrophoretically (Gordon and Pena, 1982).

The ABC affinity method used is a modification of an immunohistochemical procedure developed by Hsu et al. (1981) for studying polypeptide hormones. The ABC method was estimated to be 20 to 40 times more sensitive than the peroxidase-antiperoxidase (PAP) method. A modified ABC method, using biotinylated lectins, was faster and gave better resolution than ${ }^{125}$ I-labeled lectins when used to detect electroblotted cellsurface glycoproteins of human skin fibroblasts (Gordon and Pena, 1982). It had the further advantage of being nonradioactive. Shah and Stegemann (1986), by the same technique, discriminated between two wheat cultivars using wheat germ agglutinin (WGA) and Ulex europaeus agglutinin (UEA). These two cultivars could not be distinguished by sodium dodecyl sulphate polyacrylamide gel electrophoresis (SDS-PAGE) and isoelectric focusing. Glycoprotein profiles from four Citrus spp. and one Citrus relative were examined to determine the usefulness of the $\mathrm{ABC}$ method in glycoprotein detection in Citrus.

Leaf protein extraction. Shoots were induced on 2-year-old Citrus sinensis L. Osbeck cv. Hamlin seedlings under sodium vapor lamps (1200 $\mu \mathrm{mol} \cdot \mathrm{s}^{-1} \cdot \mathrm{m}^{-2}, 16$-h photoperiod, $25 \mathrm{C}$ ). The new, just-elongated flush of leaves was collected, washed with distilled water, dried, and the midrib removed. Leaves were frozen in liquid nitrogen and powdered with mortar and pestle. Cold (4C) extraction buffer [50 mm Tris. $\mathrm{HCl} \mathrm{pH} 8.4$, 


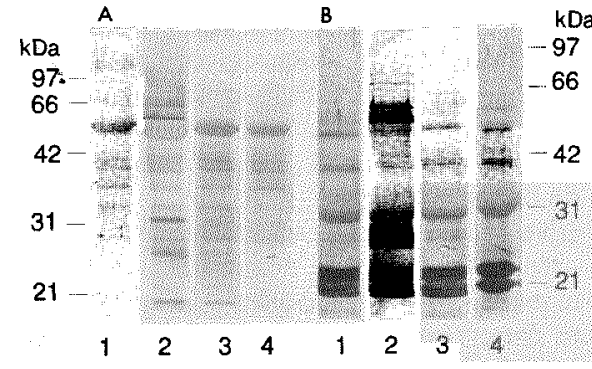

Fig. 1. Identification of lectin-binding glycoproteins in $C$. sinensis cv. Hamlin leaf and aced protein extracts on a $12 \%$ SDS-PAGE gel. (A) Leaf proteins; (B) seed proteins. Lane 1, WGA; lane 2, ConA; lane 3, PNA; lane 4, PWA. Blots were probed with $1 \mu \mathrm{g} \cdot \mathrm{ml}^{-1}$ of lectin and glycoproteins detected using the ABC technique of Hsu et al. (1981). Molecular mass markers are indicated on the left and right.

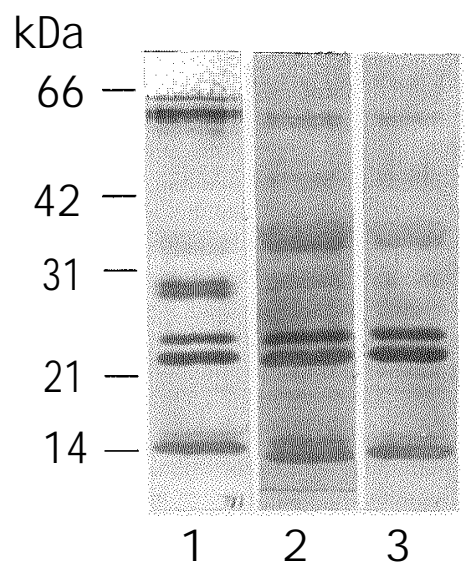

Fig. 2. Control blot to determine nonspecific lectin binding and possible endogenous alkaline phosphatase activity. Blot is seed protein extract from $C$ sinensis cv. Hamlin run on $12 \%$ SDS-PAGE. Lane 1, ConA; lane 2, ConA incubated with $0.5 \mathrm{~m} \alpha$-methyl-D-mannoside before probing; lane 3, no lectin. Molecular mass markers are indicated on the left.

$150 \mathrm{~mm} \mathrm{NaCl}, 1 \mathrm{~mm} \mathrm{CaCl}_{2}, 1 \%$ insoluble polyvinylpolypyrrolidone (PVP)] was mixed with the leaf powder $(0.5 \mathrm{ml}$ buffer per 0.1 $\mathrm{g}$ leaf tissue) and stirred for $15 \mathrm{~min}$. This solution was filtered through cheesecloth and the filtrate centrifuged for $20 \mathrm{~min}$ at $20,000 \times g$. Protein concentration was determined by the Bradford dye-binding method (Smith, 1988) using bovine serum albumin (BSA) as a standard. The supernatant was stored at $-20 \mathrm{C}$.

Seed protein extraction. Seeds from $C$. aurantium L. (sour orange), $C$. grandis $\mathrm{L}$. Osbeck (pummelo), C. sinensis cv. Hamlin (sweet orange), Poncirus trifoliata L. Rafinesque (trifoliate orange), and $C$. paradisi Macfayden cv. Conners (grapefruit) were extracted from mature fruit, air-dried, and the coats removed. Decoated seeds were ground to a paste in an analytical laboratory mill (Chemical Rubber Co., Cleveland). Cold (4C) extraction buffer was mixed $(1 \mathrm{ml} / 0.1$ g) with the seed paste and stirred for $15 \mathrm{~min}$. Subsequent steps were the same as for leaf protein extraction.

SDS-polyacrylamide gel electrophoresis
Table 1. Major ConA and WGA-binding glycoproteins in four Citrus spp. and one relative.

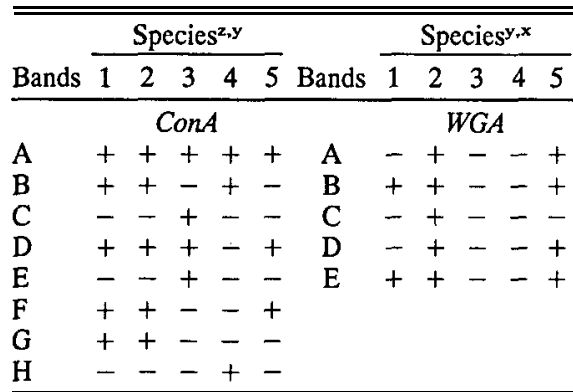

${ }^{2}$ See Fig. 3.

${ }^{\mathrm{y}}+$, Band present; -, band absent.

${ }^{\mathrm{x}}$ See Fig. 4.

and electroblotting. Leaf and seed extracts were mixed $1: 1$ and $1: 9$, respectively, with a solution containing $0.1 \mathrm{M}$ Tris $\cdot \mathrm{HCl}(\mathrm{pH}$ 6.8), $2 \%$ (v/v) glycerol, $1 \%$ (w/v) SDS, $10 \%$ $(\mathrm{v} / \mathrm{v}) 2$-mercaptoethanol and $0.0002 \%(\mathrm{w} / \mathrm{v})$ bromophenol blue. The extract then was heated for $5 \mathrm{~min}$ at $90 \mathrm{C}$ and $10 \mu \mathrm{l}$ was loaded per lane $(\approx 10 \mu \mathrm{g}$ of protein) for leaf and seed extracts. Electrophoresis was performed in a Mini-Protean II $7 \mathrm{~cm} \times 8 \mathrm{~cm}$ $\times 0.75 \mathrm{~mm}$ slab cell (Bio-Rad, Richmond, Calif.) using the Laemmli buffer system (Laemmli, 1970: 0.125 м Tris pH 6.8 stacking gel $(4 \% \mathrm{~T}, 2.67 \% \mathrm{C}), 0.375 \mathrm{M}$ Tris $\mathrm{pH}$ 8.8 separation gel $(8 \%$ and $12 \% \mathrm{~T}, 2.67 \%$ C), and Tris-glycine (0.025 M Tris, $0.192 \mathrm{M}$ glycine, $0.1 \%$ SDS, pH 8.3) electrode buffer. The proteins were separated by $40 \mathrm{~mA}$ constant current until the dye front reached the bottom of the gel, i.e., $\approx 1 \mathrm{~h}$. Bromophenol blue was used as the tracking dye and phosphorylase b (97 kDa), BSA (66 kDa), ovalbumin (42 $\mathrm{kDa})$, carbonic anhydrase (31 $\mathrm{kDa})$, soybean trypsin inhibitor $(21 \mathrm{kDa})$, and lysozyme (14 kDa) were used as molecular mass standards. Chemical reagents and standards for SDS-PAGE were purchased from Bio-Rad Laboratories.

After electrophoresis the gels were equilibrated for $30 \mathrm{~min}$ in transfer buffer: Tris/ glycine (14 mm/11 mm), 0.0375\% (w/v) SDS, pH 8.0 and $20 \%(\mathrm{v} / \mathrm{v})$ methanol. Polyvinyl difluoride (PVDF) membrane was prepared by a 20 -sec soak in methanol, three 5-min washes in distilled water, and equilibration for $15 \mathrm{~min}$ in transfer buffer. Proteins were electroblotted on PVDF (Immobilin-P, Millipore, Bedford, Mass.) transfer membrane for $30 \mathrm{~min}$ in a field strength of $1.6 \mathrm{~mA} / \mathrm{cm}^{2}$ using the LKB NovaBlot (Pharmacia LKB Biotechnology, Piscataway, N.J.).

Probing and staining. After electroblotting, the blots were washed $(3 \times, 5 \mathrm{~min})$ in Hepes buffered saline (HBS): $10 \mathrm{~mm} \mathrm{HBS}$, $150 \mathrm{~mm} \mathrm{NaCl}, \mathrm{pH} 7.5,0.1 \mathrm{mM} \mathrm{CaCl}_{2} \cdot 2 \mathrm{H}_{2} \mathrm{O}$, $0.1 \mathrm{mM} \mathrm{MgCl}_{2} \cdot 6 \mathrm{H}_{2} \mathrm{O}$ and $0.01 \mathrm{mM} \mathrm{MnCl}_{2} \cdot 4$ $\mathrm{H}_{2} \mathrm{O}$. Nonspecific lectin binding sites were blocked by incubating the blots for $30 \mathrm{~min}$ at $37 \mathrm{C}$ in HBS containing one of the following blocking agents: 1) $0.5 \%$ or $3 \%$ liquid fish gelatin (Hipure Liquid Gelatin, Norland Products, New Brunswick, N.J.), 2) 5\% defatted milk powder (Carnation Co., Los Angeles), 3) $0.1 \%$ Tween 20,4$) 0.1 \%, 0.5 \%$, or $1.0 \%$ crystallized BSA (U.S. Biochemical Corp., Cleveland). Excess blocking agent was removed by washing $(3 \times, 5 \mathrm{~min})$ in $\mathrm{HBS}$.

Biotinylated lectins Concanavalin A (Con A), pokeweed agglutinin (PWA), peanut agglutinin (PNA), and wheat germ agglutinin (WGA) were obtained from Sigma Chemical Co. (St. Louis). Lectins were dissolved in HBS containing $0.04 \%$ sodium azide and stored at $-20 \mathrm{C}$. Blots were then incubated for $60 \mathrm{~min}$ in $5 \mathrm{ml} \mathrm{HBS}$ containing biotinylated lectin at $1-50 \mu \mathrm{g} \cdot \mathrm{ml}$. To remove the unbound lectin, blots were washed $(3 \times, 5$ $\min$ ) in HBS.

An avidin-biotinylated alkaline phosphatase complex (ABC-AP) was made using the Vectastain ABC-alkaline phosphatase kit (Vector Laboratories, Burlingame, Calif.) according to the manufacturer's instructions. To detect biotin-labeled lectins, blots were first incubated in $5 \mathrm{ml} \mathrm{ABC-AP}$ solution for $90 \mathrm{~min}$ at $37 \mathrm{C}$, washed $(3 \times, 5 \mathrm{~min})$ in $\mathrm{HBS}$ to remove unbound $\mathrm{ABC}-\mathrm{AP}$, and finally equilibrated for $15 \mathrm{~min}$ before staining in substrate buffer (0.1 M Tris. $\mathrm{HCl} \mathrm{pH}$ 9.5, 0.1 $\mathrm{M} \mathrm{NaCl}$ and $50 \mathrm{~mm} \mathrm{Mg}^{2+}$ ). Alkaline phosphatase was visualized by adding $1.65 \mathrm{mg}$ nitroblue tetrazolium chloride (NBT) and 0.85 mg 5-bromo-4-chloro-3-indolylphosphate ptoluidine salt (BCIP) (Bethesda Research Laboratories, Gaithersburg, Md.) to $10 \mathrm{ml}$ substrate buffer. Blots were incubated in 5 $\mathrm{ml}$ of substrate in darkness until bands developed. The color reaction was stopped by washing the blots in $20 \mathrm{~mm}$ Tris. $\mathrm{HCl}(\mathrm{pH}$ 7.5), $5 \mathrm{~mm}$ ethylene diaminetetraacetate (EDTA)

In control experiments, the blots were treated as above but lectins were omitted, or the lectin solution contained $0.5 \mathrm{M}$ of the inhibiting saccharides for ConA and WGA, $\alpha$-methyl-D-mannoside and $\mathrm{N}$-acetylglucosamine, respectively. Experiments testing the four blocking agents were carried out with ConA only.

The increased sensitivity of the ABC method is based on the extreme affinity of the egg white glycoprotein avidin $(70,000$ MW) for biotin (dissociation constant $\left.10-{ }^{15} \mathrm{M}\right)$. As avidin has four binding sites for biotin, a "lattice" structure is believed to be formed between avidin and biotin-labeled enzyme with avidin acting as a bridge between the biotin-labeled enzyme molecules (Hsu et al., 1981). Because of the increased sensitivity, a low ligand concentration can be used resulting in minimal background staining. We found that lectin concentration was the single most important factor contributing to background staining. Concentrations $>1 \mu \mathrm{g} \cdot \mathrm{ml}^{-1}$ significantly increased the background. Band intensity was not improved with higher lectin concentrations. Background staining was also influenced by the type of blocking agent used. It is necessary to minimize nonspecific lectin binding by blocking the remaining free-binding sites on the transfer membrane after electroblotting. Of the four blocking agents tested, $1 \% \mathrm{BSA}$ resulted in less background than the others. At lower concentrations, BSA resulted in higher background. Nonfat milk 


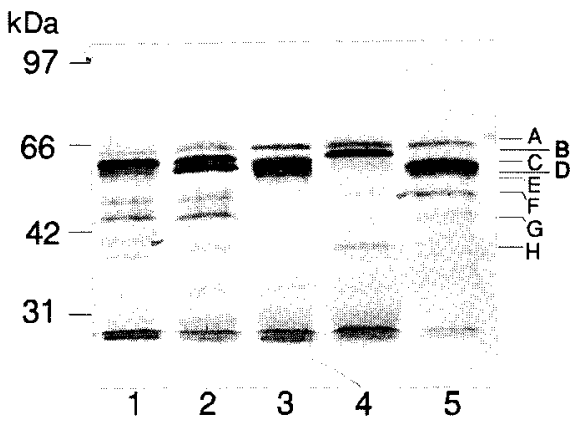

Fig. 3. ConA-binding glycoprotein profiles of four Citrus spp. and one relative run on $8 \%$ SDSPAGE. Lane 1, sour orange; lane 2, pummelo; lane 3 , sweet orange; lane 4 , grapefruit; lane 5 , trifoliate orange. Molecular mass markers are indicated on the left.

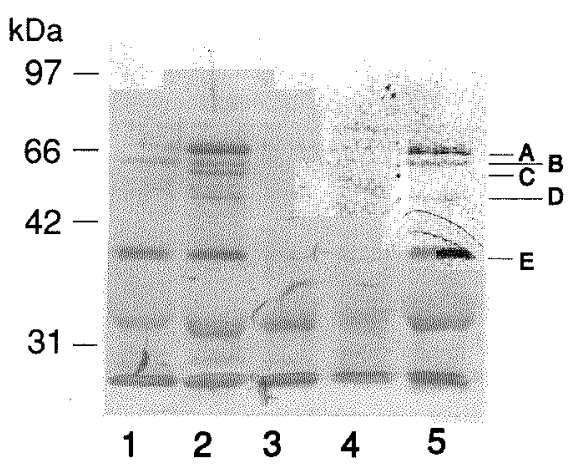

Fig. 4. WGA-binding glycoprotein profiles of four Citrus spp. and one relative run on $8 \%$ SDSPAGE. Lane 1, sour orange; lane 2, pummelo; lane 3, sweet orange; lane 4, trifoliate orange; lane 5, grapefruit. Molecular mass markers are indicated on the left.

powder decreased band intensity and increased background significantly compared with the other three blocking agents. This reaction might be due to the presence of glycoproteins recognized by ConA. Tween 20 and liquid fish gelatin resulted in good band definition but high background. In all subsequent experiments, $1 \%$ BSA was used.

Leaf and seed proteins were extracted from four Citrus spp. and one related species, run in SDS-PAGE, electroblotted, and probed with four biotinylated lectins representing three carbohydrate-binding groups (Goldstein and Poretz, 1986); ConA, a mannose/ glucose-binding lectin, WGA and PWA, Nacetylglucosamine-binding lectins, and PNA, a galactosyl end-group-binding lectin. Of the four lectins used, ConA resulted in the most prominent bands (Fig. 1). Banding profiles of seed proteins developed rapidly $(30 \mathrm{sec})$ and were much darker than those obtained from leaf proteins. A taxonomic advantage of using seed proteins is their known stability in spite of fluctuating environmental factors (Ladizinsky and Hymowitz, 1979), unlike potentially variable leaf proteins. Seed proteins and ConA were used in the majority of experiments.

Control blots were run to determine if there were any nonspecific lectin-positive bands. A blot of sweet orange seed protein probed with ConA is shown in Fig. 2. The first control (lane 2) included the inhibitory saccharides mixed with the lectin before probing. This control tests the specificity of the lectin. Other than some minor bands, there were two heavy staining bands between the $21 \mathrm{kDa}$ and $31 \mathrm{kDa}$ standards. The second control (lane 3) omitted ConA. This was an alkaline phosphatase control. The two dark bands were unchanged in the second control blot. We made no attempts to identify these bands. They may represent endogenous alkaline phosphatase, as these bands appeared when NBT and BCIP were used, chromogenic substrates for alkaline phosphatase. Also, a reductase may have reduced NBT to the insoluble formazan directly. These two bands were found in all five species. ConA-binding bands were located between $31 \mathrm{kDa}$ and 66 $\mathrm{kDa}$ and between $21 \mathrm{kDa}$ and $31 \mathrm{kDa}$ for all the species. Control blots for WGA (not shown) were similar to ConA controls in that WGA-binding bands were located between $31 \mathrm{kDa}$ and $66 \mathrm{kDa}$. Species comparisons of these two regions showed that the region from $31 \mathrm{kDa}$ to $66 \mathrm{kDa}$ was the most variable. To better resolve this region, $8 \%$ rather than $12 \%$ gels were used.

Major ConA-binding glycoproteins appeared as prominent, darkly stained bands with distinct differences between species (Fig. 3, Table 1). Minor ConA and WGA bands were not scored. Two bands just below the $31 \mathrm{kDa}$ marker were present in each species (Fig. 2, lane 1). These two bands are not visible in Fig. 3 as they ran off the gel with use of $8 \%$ acrylamide. The region between $31 \mathrm{kDa}$ and $66 \mathrm{kDa}$ contained a distinct banding profile for each species (Fig. 3). The major bands are summarized in Table 1. Band $a$, the slowest migrating band, was present in all five species. Band $\mathrm{d}$ was only faintly visible in sour orange, but prominent in pummelo. Trifoliate orange contained a large, dark staining zone that migrated at the $\mathrm{d}$ band position. Sweet orange's d band was closely sandwiched by two unique bands, c and e, not observed in the other species. Band $\mathrm{c}$ is distinct because four bands were resolved when sweet orange and grapefruit proteins were mixed, the $b$ band plus the three sweet orange bands-bands $\mathrm{c}$, d, and e. Band $\mathrm{h}$ was unique to grapefruit.

Major WGA-binding glycoprotein profiles were obtained for each species (Table 1). Bands were not as prominent as those obtained with ConA. Bands a and d were only present in pummelo and grapefruit (Fig. 4). Band a is actually two bands and band $d$ is faint, particularly in grapefruit. Band $\mathrm{c}$ was unique to pummelo and band e is actually two bands, and was present in sour orange, pummelo, and grapefruit. Band e was detected with WGA but not PWA though both lectins have the same reported sugar-binding specificity. Trifoliate orange had faint bands that migrated to the band e position, but were slightly more separated than those classified as band e.

This work demonstrates that the $\mathrm{ABC}$ affinity technique of Hsu et al. (1981) is easily adapted to the detection of plant glycopro- teins. The four Citrus spp. and one relative, $P$. trifoliata, had unique glycoprotein profiles when probed with four biotinylated lectin probes. ConA and WGA-binding glycoproteins stained as dark bands with little background staining. A single representative genotype from each of five species was used in this study to demonstrate the technique. Further characterizations are needed to determine the technique's utility in varietal identification and taxonomic classification. Lectin binding may provide additional insight into the taxonomic relationships between Citrus spp. and relatives, and be useful as a detection method in the further characterization and study of citrus glycoproteins.

\section{Literature Cited}

Barrett, H.C. and A.M. Rhodes. 1976. A numerical taxonomic study of affinity relationships in cultivated Citrus and its close relatives. Systematic Botany 1(2): 105-136.

Chicken, C.A. and F.J. Sharom. 1983. The concanavalin A receptor from human erythrocytes in lipid bilayer membranes; interaction with concanavalin A and succinyl-concanavalin A. Biochim. Biophys. Acta 729:200-208.

Chu, F.K., F.M. Maley, and A.L. Tarentino. 1981. The use of iodinated lectins for determining the degree of deglycosylation of high-mannose glycoproteins by endo- $\beta$-N-acetylglucosaminidase H. Anal. Biochem. 116:152-160.

Goldstein, I.J. and R.D. Poretz. 1986. Isolation, physiochemical characterization, and carbohydrate-binding specificity of lectins, p. 35-247. In: LE. Liener, N. Sharon, and I.J. Goldstein (eds.). The lectins: properties, functions, and applications in biology and medicine. Academic, Orlando, Fla.

Gordon, B.B. and S.D.J. Pena. 1982. The surface glycoproteins of human skin fibroblasts detected after electrophoresis by the binding of peanut (Arachis hypogaea) agglutinin and $R i$ cinus communis (castor-bean) agglutinin I. Biochem. J. 208:351-358.

Hsu, S-M., L. Raine, and H. Fanger. 1981. Use of avidin-biotin-peroxidase complex $(\mathrm{ABC})$ in immunoperoxidase techniques: A comparison between $\mathrm{ABC}$ and unlabeled antibody (PAP) procedures. J. Histochem. Cytochem. 29:577580.

Ladizinsky, G. and T. Hymowitz. 1979. Seed protein electrophoresis in taxonomic and evolutionary studies. Theor. Applied Genet. 54:145151

Laemmli, U.K. 1970. Cleavage of structural proteins during the assembly of the head of bacteriophage T4. Nature (London) 227:680-685.

Morimoto, J. 1977. Identification of Citrus species by phytoserological methods. Proc. Intl. Soc. Citriculture 2:625-631.

Pena, S.D.J., B.B. Gordon, G. Karpati, and S. Carpenter. 1981. Lectin histochemistry of human skeletal muscle. J. Histochem. Cytochem. 29:542-546

Rouseff, R.L., S.F. Martin, and C.O. Youtsey. 1987. Quantitative survey of narirutin, naringin, hesperidin, and neohesperidin in Citrus. J. Agr. Food Chem. 35:1027-1030.

Shah, V.A.A. and H. Stegemann. 1986. Lectinbased characterization of glycoproteins in plants and its application to cultivar discrimination. Nachrichtenbl. Deut. Pflanzenschutzd. 38:100103

Smith, J.A. 1988. Quantitation of proteins, p. 
10.1.1-10.1.3. In: F.M. Ausubel, R. Brent, R.E. Kingston, D.D. Moore, J.G. Seidman, J.A. Smith, and K. Struhl (eds.). Current protocols in molecular biology, vol. 2. Wiley, New York. Tanaka, T. 1977. Fundamental discussion of Citrus classification. Studia Citrogia 14:1-6.
Torres, A.M., R.K. Soost, and U. Diedenhofen. 1978. Leaf isozymes as genetic markers in citrus. Amer. J. Bot. 65(8):869-881. 